\title{
EDITORIAL
}

\section{The implication of context in applying learning technologies}

The six articles in this issue offer guidance to educators in the application of learning technology in different contexts. The first three articles are aimed at those employing learning technology on specific educational contexts - informal and formal - whilst the fourth deals with inclusion countrywide. The last two articles offer valuable insights into learner behaviours and skills in changing technological contexts.

Laine, Vinni, Sedano and Joy draw on their experiences of developing Myst to offer a set of design principles for pervasive game platforms to be used in various contexts.

In their multi-site study of video-linked lectures for healthcare students Wang, Mattick and Dunne found that students' tendency to prefer live lectures at the home site created a challenge for multi-site videoing of lectures; but that student attendance at live lectures was more affected by topic and speaker than the availability of a video version.

Mogey, Paterson, Burk and Purcell explored the offering of a choice to students of handwriting or word-processing their answers to essay examinations. There were no significant differences attributable to writing format though the variation between the markers was striking.

From a review of the literature, Alebaikan and Troudi identify challenges in the application of blended learning to Saudi Higher Education that are also relevant to those facing similar challenges.

Barnard-Brak, Paton and Lan conclude from their study that self-regulatory skills are not automatically developed with students' online learning experiences, and that the design of online courses needs to consider ways of developing these skills.

The evidence from Winter, Cotton, Gavin and Yorke's study of effective e-learners highlights their ability to multi-task between learning and non-learning activities. Students' use of boundary management techniques is particularly relevant where Web 2.0 is used in educational activities.

Frances Bell

University of Salford, UK 